\section{Brazilian Journal of Chemical Engineering}

ISSN 0104-6632

Printed in Brazil

www.abeq.org.br/bjche

Vol. 33, No. 03, pp. 637 - 647, July - September, 2016

dx.doi.org/10.1590/0104-6632.20160333s20150116

\title{
MODELING STYRENE HYDROGENATION KINETICS USING PALLADIUM CATALYSTS
}

\author{
G. T. Justino ${ }^{1}$, C. S. A. Vale ${ }^{1}$, M. A. P. da Silva ${ }^{1 *}$ and A. R. Secchi ${ }^{2}$ \\ ${ }^{1}$ Escola de Química, UFRJ, Av. Athos da Silveira Ramos, 149 Bloco E, \\ Ilha do Fundão, CEP: 21941-909, Rio de Janeiro - RJ, Brazil. \\ Phone: (55) (21) 3938-7606; Fax: (55) (21) 3938-7567 \\ E-mail:monica@eq.ufrj.br \\ ${ }^{2}$ Programa de Engenharia Química, COPPE, Universidade Federal do \\ Rio de Janeiro, Rio de Janeiro - RJ, Brazil
}

(Submitted: February 25, 2015 ; Revised: August 28, 2015 ; Accepted: October 9, 2015)

\begin{abstract}
The high octane number of pyrolysis gasoline (PYGAS) explains its insertion in the gasoline pool. However, its use is troublesome due to the presence of gum-forming chemicals which, in turn, can be removed via hydrogenation. The use of Langmuir-Hinshelwood kinetic models was evaluated for hydrogenation of styrene, a typical gum monomer, using $\mathrm{Pd} / 9 \% \mathrm{Nb}_{2} \mathrm{O}_{5}-\mathrm{Al}_{2} \mathrm{O}_{3}$ as catalyst. Kinetic models accounting for hydrogen dissociative and non-dissociative adsorption were considered. The availability of one or two kinds of catalytic sites was analyzed. Experiments were carried out in a semi-batch reactor at constant temperature and pressure in the absence of transport limitations. The conditions used in each experiment varied between $16-56$ bar and $60-100{ }^{\circ} \mathrm{C}$ for pressure and temperature, respectively. The kinetic models were evaluated using MATLAB and EMSO software. Models using adsorption of hydrogen and organic molecules on the same type of site fitted the data best.

Keywords: Pyrolysis gasoline; Hydrotreatment; Styrene; Kinetic models.
\end{abstract}

\section{INTRODUCTION}

Pyrolysis gasoline (PYGAS) is a side product of petroleum naphtha pyrolysis. It is a mixture of $\mathrm{C}_{5}$ to $\mathrm{C}_{12}$ hydrocarbons, the main components being BTX aromatics (benzene, toluene, and xylene). Styrene, mono and diolefins are also present in PYGAS in appreciable proportions. The high octane number of PYGAS is responsible for its insertion in the gasoline pool (Nijhuis et al., 2003).

However, the gum-forming properties of styrene, mono and diolefins hinders its actual participation on the gasoline pool. Compounds containing sulfur and nitrogen also need to be removed from PYGAS (Ali, 2012). In addition to that, recent changes in envi- ronmental legislation in Brazil now require much lower concentrations of aromatics in gasoline, thus demanding development of processes for this end (Gaspar et al., 2008).

The best way to get rid of these chemicals while maintaining the high octane number of PYGAS is via a selective hydrogenation process, which occurs in two stages (Cheng et al., 1986; Rojas and Zeppieri, 2014). In the first one, styrene and diolefins are selectively hydrogenated under moderate conditions to prevent gum and coke formation. The reactor temperature and hydrogen pressure are in the range of 50 $-130^{\circ} \mathrm{C}$ and $20-40$ bar, respectively (Cheng et al., 1986; Medeiros et al., 2007). In the second stage, sulfur compounds are converted and mono-olefins are

*To whom correspondence should be addressed

This is an extended version of the work presented at the 20th Brazilian Congress of Chemical Engineering, COBEQ-2014, Florianópolis, Brazil. 
hydrogenated using higher temperatures (Mostoufi et al., 2005). Currently, the first stage is carried out using $\mathrm{Pd}$ catalysts while the second uses $\mathrm{CoMo} / \mathrm{Al}_{2} \mathrm{O}_{3}$ regenerable catalysts (Cheng et al., 1986; Gaspar et al., 2008). It is well established that, during the first stage, hydrogenation of mono-olefins is not significant, since selectivity to adsorption onto Pd catalytic sites is much greater for diolefins as compared to mono-olefins. Thus, hydrogenation of mono-olefins occurs only after reducing of diolefins concentration.

The first hydrogenation stage is sufficient for the production of a stable mixture with high octane number, which can be added to the gasoline pool. Further processing in the second stage normally occurs when PYGAS is used for aromatic extraction. If the objective is the insertion in the gasoline pool, this stage can be by-passed, unless the initial composition of the PYGAS and the local legislation require a further reducing in aromatics and sulfur concentration (Cheng et al., 1986; Ali, 2012).

In this work, PYGAS was simulated with a solution of styrene in toluene. Styrene was selected as a model molecule regarding PYGAS since it is one of the less reactive of its components (Cheng et al., 1986; Nijhuis et al., 2003; Gaspar et al., 2008).

The kinetic parameters of PYGAS hydrogenation over a $\mathrm{Pd} / \mathrm{Al}_{2} \mathrm{O}_{3}$ catalyst were initially investigated by Cheng et al. (1986) using a power-law model which assumed an order of reaction equal to 1 for both styrene and hydrogen. Ali (2012) also assumed first order with respect to styrene and estimated as 0.1 the order of reaction for hydrogen, and Tukac et al. (2007) estimated order 1 for hydrogen and 0.5 for styrene. Jackson and Shaw (1996) found a completely different result for styrene hydrogenation over a $\mathrm{Pd} /$ carbon catalyst: assuming zero order for hydrogen, they estimated also zero order for styrene. This result might indicate that Langmuir-Hinshelwood models could be a good representation for the reaction rate.

Kinetic studies of PYGAS hydrogenation over $\mathrm{Pd} / \mathrm{Al}_{2} \mathrm{O}_{3}$ and $\mathrm{Pd}-\mathrm{Ni} / \mathrm{Al}_{2} \mathrm{O}_{3}$ catalyst were investigated by Zhou et al. (2007; 2010) and Abreu et al. (2013), respectively. Mixtures of styrene, olefins and diolefins were employed to represent PYGAS. These authors obtained good fits for styrene hydrogenation using Langmuir-Hinshelwood models considering dissociative hydrogen adsorption and the existence of two kinds of catalytic sites for the adsorption of organic compounds and hydrogen. Styrene hydrogenation was also carried out in a trickle-bed reactor over $\mathrm{Pd} / \mathrm{Al}_{2} \mathrm{O}_{3}$ by Nijhuis et al. (2003) and Fraga (2009). These authors obtained good fits with Lang-
muir-Hinshelwood models considering the nondissociative mechanism for hydrogen adsorption.

Recently, the effects of supports for Pd catalyst have been studied for PYGAS hydrogenation. Gaspar et al. (2008) investigated the addition of $\mathrm{ZrO}_{2}$ in different loadings on $\mathrm{Al}_{2} \mathrm{O}_{3}$ for hydrogenation of a model mixture representative of PYGAS. However, the $\mathrm{Pd} / \mathrm{Al}_{2} \mathrm{O}_{3}$ catalyst was still the most active. Zeng et al. (2009) tested a Pd catalyst on macro-mesoporous $\mathrm{TiO}_{2}$ and obtained satisfactory results when compared with a $\mathrm{Pd} / \mathrm{TiO}_{2}$ catalyst of microporous morphology. Corvaisier et al. (2013) evaluated different metal catalysts supported on $\mathrm{SiO}_{2}$ for styrene hydrogenation, obtaining highest activity for $\mathrm{Pd} / \mathrm{SiO}_{2}$, but no comparison with the traditional $\mathrm{Pd} / \mathrm{Al}_{2} \mathrm{O}_{3}$ catalyst was made. These authors obtained a good fit with a Langmuir-Hinshelwood model considering the dissociative adsorption of hydrogen and only one type of catalytic site was tested.

Betti et al. (2016) investigated styrene hydrogenation using a palladium catalyst supported on an inorganic-organic composite. Horiuti-Polanyi and Langmuir-Hinshelwood mechanisms were considered for hydrogenation and adsorption, respectively. The best fit was obtained for the model considering the competitive adsorption of all compounds, only one type of catalytic site, and dissociative adsorption of hydrogen.

Previous work of the group (Vale, 2013) studied the niobia-modified alumina-supported palladium catalyst $\left(\mathrm{x} \mathrm{Nb}_{2} \mathrm{O}_{5}-\mathrm{Al}_{2} \mathrm{O}_{3}\right.$, with $9 \%$ and $18 \%$ of $\mathrm{Nb}_{2} \mathrm{O}_{5}$ in weight) and the effects on styrene hydrogenation when compared to $\mathrm{Pd} / \mathrm{Al}_{2} \mathrm{O}_{3}$. The most active catalyst was the one with $9 \% \mathrm{w} / \mathrm{w}$ of niobia. Consequently, in the present work the $\mathrm{Pd} / 9 \% \mathrm{Nb}_{2} \mathrm{O}_{5}-\mathrm{Al}_{2} \mathrm{O}_{3}$ catalyst was chosen to evaluate the kinetic models for styrene hydrogenation. Kinetic parameters of the power-law and Langmuir-Hinshelwood models were estimated based on experiments carried out in a semi-batch bench scale reactor.

\section{EXPERIMENTAL}

\section{Catalyst}

The composition of the catalyst was $1 \% \mathrm{w} / \mathrm{w}$ of palladium and $9 \% \mathrm{w} / \mathrm{w}$ of $\mathrm{Nb}_{2} \mathrm{O}_{5}$. Palladium dispersion was determined as $13 \%$ by hydrogen chemisorption assuming a 1:2 $\left(\mathrm{H}_{2}: \mathrm{Pd}\right)$ ratio. Specific area and pore volume, obtained using nitrogen adsorption, were $179 \mathrm{~m}^{2} / \mathrm{g}$ and $0.47 \mathrm{~cm}^{3} / \mathrm{g}$, respectively (Alegre et al., 2006). 


\section{Styrene Solution Preparation}

Initially, styrene was purified to eliminate tertbutyl-catechol, a stabilizer which is known to interfere with the catalyst activity (Hoffer et al., 2004; Wen et al., 2013). Toluene, used as solvent, was also purified for the removal of water since it decreases the reaction rate (Wolffenbuttel et al., 2001). Solutions of styrene in toluene were prepared right before each catalytic test, with concentrations ranging from 0.3 to $0.8 \mathrm{~mol} / \mathrm{L}$.

\section{Styrene Hydrogenation}

Styrene hydrogenation was carried out in a Parr reactor $(0.160 \mathrm{~L})$ operated at $600 \mathrm{rpm}$ under constant temperature and pressure. The $\mathrm{Pd} / 9 \% \mathrm{Nb}_{2} \mathrm{O}_{5}-\mathrm{Al}_{2} \mathrm{O}_{3}$ catalyst was prepared by impregnation. The detailed experimental procedure is presented elsewhere (Alegre et al., 2006). The catalyst $\mathrm{Pd} / 9 \% \mathrm{Nb}_{2} \mathrm{O}_{5}-\mathrm{Al}_{2} \mathrm{O}_{3}$ (approximately $0.0150 \mathrm{~g}$ ) was previously reduced in situ under pure $\mathrm{H}_{2}$ (10 bar) at $150{ }^{\circ} \mathrm{C}$ for 1 hour. After reduction, the reactor was cooled to room temperature. Then, $0.105 \mathrm{~L}$ of reaction mixture was introduced into the reactor under $\mathrm{H}_{2}$ atmosphere, which was then heated to the desired temperature. Next, the zero $^{\text {th }}$ aliquot was taken, the reactor was pressurized and the agitation $(600 \mathrm{rpm})$ initiated. The experimental conditions were chosen to reduce the effects of mass transport limitations. Aliquots taken at intervals of 5 min during $1 \mathrm{~h}$ of reaction were analyzed in a HP 6890N chromatograph, equipped with a DB1 column (60 m X $0.32 \mathrm{~mm}$ ) and a flame ionization detector (FID).

Two sets of experiments were carried out to estimate kinetic parameters of the studied models. In the first set of experiments, the temperature was fixed at $80{ }^{\circ} \mathrm{C}$, which is inside the temperature range of $50-$ $130{ }^{\circ} \mathrm{C}$ used industrially (Medeiros et al., 2007). Five levels of $\mathrm{H}_{2}$ pressure $(16,26,36,46$, and 56 bar) and three levels of styrene concentration $(0.3,0.5$ and 0.8 $\mathrm{mol} / \mathrm{L})$ were used. The parameter estimation using this first data set resulted in the knowledge of the expected values for the equilibrium constants of adsorption at the reference temperature $\left(T_{R}\right)$ and for the pre-screening of the kinetic models.

The second set of experiments includes the effects of temperature on the styrene hydrogenation with five levels $\left(60,70,80,90\right.$, and $\left.100^{\circ} \mathrm{C}\right)$. In this set, the effects of $\mathrm{H}_{2}$ pressure were evaluated at the same five levels mentioned previously, and the initial styrene concentration was kept at $0.5 \mathrm{~mol} / \mathrm{L}$ in all these new experiments. With this additional set of experiments, it was also possible to estimate the apparent activation energy and heats of adsorption of styrene, hydrogen and ethylbenzene.

\section{KINETIC MODELING}

All measurements were carried out in the kinetic regime. The external diffusion effect was eliminated by a sufficiently effective stirring, and the pore diffusion effect was eliminated by the use of a sufficiently small particle size.

The molar balances can be written as follows:

$$
\begin{aligned}
& \left(-r_{s}\right)=-\frac{V}{m_{\text {cat }}} \frac{d C_{s}}{d t} \\
& r_{e}=\frac{V}{m_{c a t}} \frac{d C_{e}}{d t}
\end{aligned}
$$

where:

$\left(-r_{s}\right)=$ rate of disappearance of styrene $(\mathrm{mol} /(\mathrm{min}$

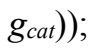

$r_{e}=$ rate of formation of ethylbenzene $(\mathrm{mol} /(\mathrm{min}$ $\left.\mathrm{g}_{\text {cat }}\right)$;

$C_{s}$ and $C_{e}=$ styrene and ethylbenzene concentrations $(\mathrm{mol} / \mathrm{L})$;

$m_{\text {cat }}=$ catalyst mass $\left(g_{c a t}\right)$;

$V=$ volume of reaction mixture (L).

Two power-law models were fitted to the styrene hydrogenation data, using the rate expressions shown in Table 1. Model PL_ $\alpha \beta$ gives individual reaction orders for styrene and hydrogen. Model PL_ $\beta$ imposes first-order kinetics regarding styrene, allowing the $\mathrm{H}_{2}$ order to be determined.

Table 1: Power-law kinetic models.

\begin{tabular}{|l|c|}
\hline Model & Rate equation $\left(-\boldsymbol{r}_{\boldsymbol{s}}\right)$ \\
\hline $\mathrm{PL} \_\alpha \beta$ & $k C_{s}{ }^{\alpha} C_{H}{ }^{\beta}$ \\
$\mathrm{PL} \_\beta$ & $k C_{s} C_{H}{ }^{\beta}$ \\
\hline
\end{tabular}

Langmuir-Hinshelwood models with three and four parameters were also evaluated, considering the surface reaction of adsorbed species as the limiting step. The evaluated models consider adsorption of organic compounds and hydrogen on the same type of active site or on two types of active sites (one of which adsorbs hydrogen and the other adsorbs organic molecules). The corresponding rate expressions are shown in Tables 2 and 3, where $k$ is the specific rate and $K_{i}$ and $C_{i}$ are, respectively, the 
adsorption constant and the concentration of compounds $i$ (styrene, ethylbenzene, or hydrogen). In the nomenclature of the kinetic models, the Roman numerals represent the number of types of active sites, and the prefixes account for the dissociative mechanism of hydrogen adsorption (models D), as well as for the non-dissociative one (models ND). The suffixes $\mathrm{S}, \mathrm{E}$ and $\mathrm{H}$ represent the inclusion in the rate expression of the corresponding adsorption terms for styrene, ethylbenzene and hydrogen, respectively, in the denominator.

Table 2: Langmuir-Hinshelwood kinetic models with three parameters.

\begin{tabular}{|c|c|c|}
\hline Model & Rate equation $\left(-\boldsymbol{r}_{s}\right)$ & $\boldsymbol{K}_{\text {global }}$ \\
\hline ND_I_SE & $\frac{K_{\text {global }} C_{H} C_{s}}{\left(1+K_{s} C_{s}+K_{e} C_{e}\right)^{2}}$ & $k K_{s} K_{H}$ \\
D_I_SE & $\frac{K_{\text {global }} C_{H} C_{s}}{\left(1+K_{s} C_{s}+K_{e} C_{e}\right)^{3}}$ & $k K_{s} K_{H}$ \\
ND_II_SE & $\frac{K_{\text {global }} C_{H} C_{s}}{\left(1+K_{s} C_{s}+K_{e} C_{e}\right)}$ & $k K_{s} K_{H}$ \\
D_IISSE & $\frac{K_{\text {global }} \sqrt{C_{H} C_{s}}}{\left(1+K_{s} C_{s}+K_{e} C_{e}\right)}$ & $k K_{s} \sqrt{K_{H}}$ \\
ND_I_SH & $\frac{K_{\text {global }} C_{H} C_{s}}{\left(1+K_{s} C_{s}+K_{H} C_{H}\right)^{2}}$ & $k K_{s} K_{H}$ \\
D_I_SH & $\frac{K_{\text {global }} C_{H} C_{s}}{\left(1+K_{s} C_{s}+\sqrt{K_{H} C_{H}}\right)^{3}}$ & $k K_{s} K_{H}$ \\
ND_II_SH & $\frac{K_{\text {global }} C_{H} C_{s}}{\left(1+K_{s} C_{s}\right)\left(1+K_{H} C_{H}\right)}$ & $k K_{s} K_{H}$ \\
D_II_SH & $\frac{K_{\text {global }} \sqrt{C_{H} C_{s}}}{\left(1+K_{s} C_{s}\right)\left(1+\sqrt{K_{H} C_{H}}\right)}$ & $k K_{s} \sqrt{K_{H}}$ \\
\hline
\end{tabular}

Table 3: Langmuir-Hinshelwood kinetic models with four parameters.

\begin{tabular}{|c|c|c|}
\hline Model & Rate equation $\left(-\boldsymbol{r}_{\boldsymbol{s}}\right)$ & $\boldsymbol{K}_{\text {global }}$ \\
\hline ND_I_SEH & $\frac{K_{\text {global }} C_{H} C_{s}}{\left(1+K_{s} C_{s}+K_{e} C_{e}+K_{H} C_{H}\right)^{2}}$ & $k K_{s} K_{H}$ \\
D_I_SEH & $\frac{K_{\text {global }} C_{H} C_{s}}{\left(1+K_{s} C_{s}+K_{e} C_{e}+\sqrt{K_{H} C_{H}}\right)^{3}}$ & $k K_{s} K_{H}$ \\
ND_II_SEH & $\frac{K_{\text {global }} C_{H} C_{s}}{\left(1+K_{s} C_{s}+K_{e} C_{e}\right)\left(1+K_{H} C_{H}\right)}$ & $k K_{s} K_{H}$ \\
D_II_SEH & $\frac{K_{\text {global }} \sqrt{C_{H} C_{s}}}{\left(1+K_{s} C_{s}+K_{e} C_{e}\right)\left(1+\sqrt{K_{H} C_{H}}\right)}$ & $k K_{s} \sqrt{K_{H}}$ \\
\hline
\end{tabular}

The effect of temperature on the specific rate and the adsorption constant was described by the Arrhenius and Van't Hoff equations, respectively, which were used in parameterized forms, given by Equations (3) and (4), to reduce the parametric correlation
(Schwaab and Pinto, 2008). In these expressions, $T$ is the reaction temperature, $T_{R}$ is a reference temperature $\left(80{ }^{\circ} \mathrm{C}\right.$, the mean temperature in the evaluated range), $R$ is the universal gas constant, $\delta$ is equal to $1 / 2$ for the models with two types of active sites and dissociative hydrogen adsorption and equal to 1 for all other Langmuir-Hinshelwood models, and $a_{i}$ and $b_{i}$ are the fitting parameters, related to the frequency factor $\left(k^{0}\right)$, apparent activation energy $(E)$, adsorption constant $\left(K_{i}^{0}\right)$, and heat of adsorption $\left(Q_{i}\right)$ as described in Equations (5) - (8).

$$
\begin{aligned}
& K_{\text {global }}=\exp \left(a_{\text {global }}+b_{\text {global }}\left(1-\frac{T_{R}}{T}\right)\right) \\
& K_{i}=\exp \left(a_{i}+b_{i}\left(1-\frac{T_{R}}{T}\right)\right) \\
& E=R T_{R} b_{\text {global }}-Q_{s}-\delta Q_{H} \\
& Q_{i}=R T_{R} b_{i} \\
& K_{\text {global }}^{0}=\exp \left(a_{\text {global }}+b_{\text {global }}\right)=k^{0} K_{S}^{0}\left(K_{H}^{0}\right)^{\delta} \\
& K_{i}^{0}=\exp \left(a_{i}+b_{i}\right)
\end{aligned}
$$

The softwares MATLAB and EMSO (Soares and Secchi, 2003) were employed for parameter estimation and statistical analysis of the obtained experimental data, adopting a confidence interval of $95 \%$. For the evaluation of the effects of pressure and styrene concentration, the parameters were estimated based on 64 data points obtained from 10 experiments at $80{ }^{\circ} \mathrm{C}$ (first data set). To evaluate the effect of temperature on styrene hydrogenation, all 116 data points obtained from 18 experiments from both data sets were used. A hybrid optimization method, consisting of the Adaptive Random Search (Secchi and Perlingeiro, 1989) for global search and Flexible Polyhedra (Nelder and Mead, 1965) for solution refinement to a relative accuracy of $10^{-4}$ for the parameters, was used to solve the maximum likelihood problem, given by the objective function presented in Equation (9), with relative and absolute accuracy of $10^{-6}$ and $10^{-8}$, respectively, for numerical integration of Equations (1) and (2). The hydrogen concentration in the liquid phase was calculated from a simple flash calculation with HYSIS software using the SRK equation of state (Zhou et al., 2006). 
$F_{o b j}=\sum_{i} \sum_{j} \sum_{t}\left(\frac{C_{i, j, t}^{e}-C_{i, j, t}^{p}}{\sigma_{i}}\right)^{2}$

where:

$i=$ styrene, ethylbenzene

$j=$ experiment number

$t=$ time $(\min )$

$C_{i, j, t}^{e}=$ experimental concentration of substance $i$, in experiment $j$ and at time $t$

$C_{i, j, t}^{p}=$ predicted concentration of substance $i$, in experiment $j$ and at time $t$

$\sigma_{i}=$ standard deviation of $C_{i, j, t}^{e}$.

\section{RESULTS AND DISCUSSION}

\section{Effect of Pressure and Styrene Concentration}

At first, only the effects of hydrogen pressure and styrene concentration were evaluated. In this stage, the estimation of the kinetic parameters was based on the experimental data obtained at $80{ }^{\circ} \mathrm{C}$. Table 4 shows these parameters for the power-law models.

Table 4: Estimated parameters for the power-law models.

\begin{tabular}{|c|c|c|c|c|c|}
\hline Model & Specific Rate & $\boldsymbol{\alpha}$ & $\boldsymbol{\beta}$ & $\begin{array}{l}\text { Objective } \\
\text { Function }\end{array}$ & $\mathbf{R}^{2}$ \\
\hline PL_ $\alpha \beta$ & $\begin{array}{c}(8.8 \pm 8.3) \times 10^{2} \\
\mathrm{~L}^{1.2} /\left(\mathrm{mol}^{0.2} \mathrm{~min}_{\mathrm{cat}}\right)\end{array}$ & $0.5 \pm 0.1$ & $0.7 \pm 0.1$ & 4875.02 & 0.880 \\
PL_$\beta$ & $\begin{array}{c}(1.6 \pm 1.0) \times 10^{3} \\
\mathrm{~L}^{1.7} /\left(\mathrm{mol}^{0.7} \mathrm{~min}_{\mathrm{cat}}\right)\end{array}$ & & $0.7 \pm 0.1$ & 5933.04 & 0.855 \\
\hline
\end{tabular}

According to Cheng et al. (1986) and Ali (2012), the order of reaction with respect to styrene is 1 , corroborating the hypothesis of the PL_ $\beta$ model, whereas Tukac et al. (2007) estimated an order of 0.5 for styrene, ratifying the PL_ $\alpha \beta$ model. However, Jackson and Shaw (1995) estimated zero order of reaction with respect to styrene, suggesting that Langmuir-Hinshelwood models are plausible options to represent the reaction rate.

In both power-law models, the order of reaction with respect to hydrogen of 0.7 was close to the value of 0.6 estimated by Vale (2013), and the first order reaction assumed by Cheng et al. (1986) and estimated by Tukac et al. (2007). Nijhuis et al. (2003) also observed a first order with respect to hydrogen for pressures below 20 bar; with higher hydrogen pressures, the reaction rate stabilized, suggesting the viability of Langmuir-Hinshelwood models. However, our estimated result differs from Ali (2012), which estimated the order of reaction with respect to hydrogen as 0.1, and Jackson and Shaw (1995), which fixed this parameter as zero.

It was observed that the error in the specific rate in both models was very high, in addition to having the lowest coefficients of determination of all evaluated models, suggesting that power-law models do not describe well the experimental data. This occurs because power-law models do not represent accurately the competition for the catalytic sites between the reactants. The fittings of the power-law models to the experimental data are shown in Figure 1.
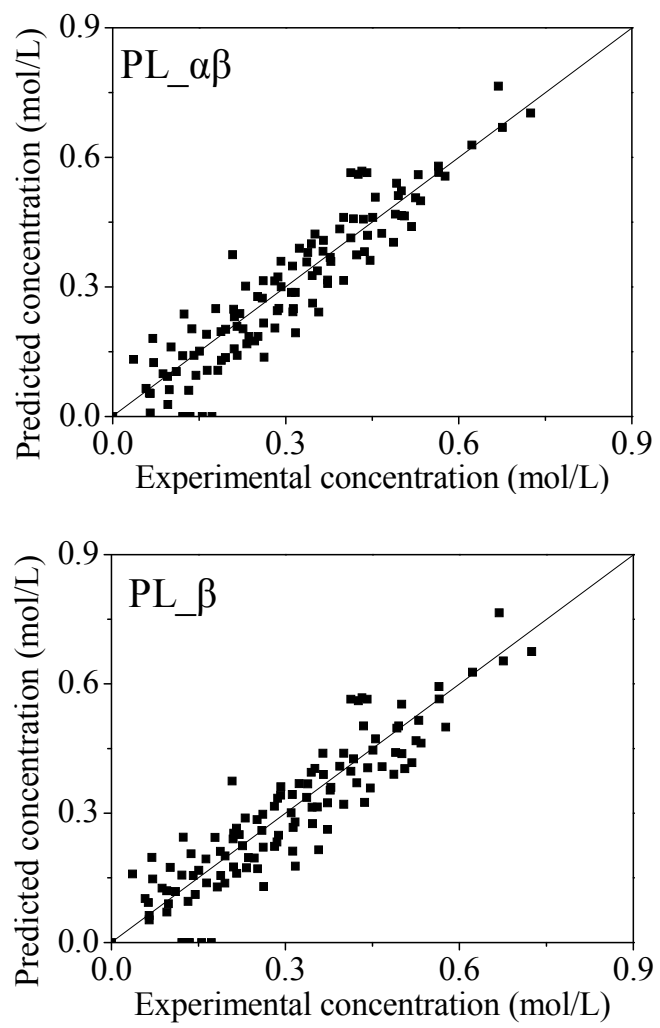

Figure 1: Fittings of the power-law models.

Tables 5 to 7 exhibit the estimated parameters for the evaluated Langmuir-Hinshelwood models. The models that considered the adsorption of organic compounds and hydrogen on the same type of catalytic site provided a better fit to the experimental data.

For the models ND_I_SE, ND_II_SE and D_II_SE, it was observed that the errors associated with each parameter are high, showing that these models do not 
have statistical significance. In contrast, the model D_I_SE presents a good fit to the experimental data and statistically significant parameters, being the best among the models that neglect the hydrogen adsorption.

Regarding the models that consider negligible the ethylbenzene adsorption, whose results are shown in Table 5, it can be seen that the models ND_I_SH, D_I_SH, and ND_II_SH show statistical significance. However, when compared to the other threeparameter models, described in Table 4, it can be seen that these models do not exhibit good fits to the experimental data. In addition, the results for the equilibrium constant for hydrogen adsorption are higher than the values found for the equilibrium constant of styrene adsorption, in disagreement with the literature (Zhou et al., 2007; 2010). In this respect, only the model D_II_SH presents results in accordance with the literature, but the equilibrium constant for hydrogen adsorption is not a significant parameter, given its high confidence interval.

For the four-parameter models, it was found that the models ND_I_SEH, D_I_SEH and ND_II_SEH show statistical significance, while the model D_II_SEH presented $K_{H}$ equal to zero and with no statistical significance. As demonstrated by the values of the objective function and the determination coefficient, shown in Table 6 , the model ND_I_SEH best represents the experimental data among the four-parameter models. Its parameters also showed high statistical significance. The fittings of the models ND_I_SEH, D_I_SEH and ND_II_SEH to the experimental data are shown in Figure 2 .

Table 5: Estimated parameters for the Langmuir-Hinshelwood models ND_I_SE to D_II_SE.

\begin{tabular}{|l|c|c|c|c|c|}
\hline Model & $\boldsymbol{K}_{\text {global }}$ & $\begin{array}{c}\boldsymbol{K}_{\boldsymbol{s}} \\
(\mathbf{L} / \mathbf{m o l})\end{array}$ & $\begin{array}{c}\boldsymbol{K}_{\boldsymbol{e}} \\
(\mathbf{L} / \mathbf{m o l})\end{array}$ & $\begin{array}{c}\text { Objective } \\
\text { Function }\end{array}$ & $\mathbf{R}^{\mathbf{2}}$ \\
\hline ND_I_SE & $38.7 \pm 39.3$ & $4.4 \pm 3.1$ & $4.3 \pm 3.2$ & 3750.71 & 0.921 \\
D_I_SE & $15.6 \pm 6.4$ & $1.3 \pm 0.4$ & $1.2 \pm 0.5$ & 3766.71 & 0.918 \\
ND_II_SE & $37.1 \pm 33.4$ & $20.3 \pm 19.1$ & $18.6 \pm 19.6$ & 3914.63 & 0.908 \\
D_II_SE & $35.4 \pm 22.8$ & $73.0 \pm 47.8$ & $49.2 \pm 39.3$ & 4382.28 & 0.904 \\
\hline
\end{tabular}

${ }^{1}$ The measurement units of $K_{\text {global }}$ are L ${ }^{2} /\left(\mathrm{mol} \min \mathrm{g}_{\mathrm{cat}}\right)$ for the models ND_I_SE, D_I_SE and ND_II_SE and L $\mathrm{L}^{1.5} /\left(\mathrm{mol}^{0.5} \mathrm{~min}_{\mathrm{gcat}}\right)$ for the model D_II SE.

Table 6: Estimated parameters for the Langmuir-Hinshelwood models ND_I_SH to D_II_SH.

\begin{tabular}{|c|c|c|c|c|c|c|}
\hline Model & $K_{\text {global }}{ }^{1}$ & $K_{s}(\mathrm{~L} / \mathrm{mol})$ & $K_{H}(\mathrm{~L} / \mathrm{mol})$ & \begin{tabular}{|c|}
$k$ \\
$\left(\mathrm{~mol} /\left(\mathrm{min} \mathrm{g}_{\mathrm{cat}}\right)\right)$ \\
\end{tabular} & $\begin{array}{l}\text { Objective } \\
\text { Function }\end{array}$ & $\mathbf{R}^{2}$ \\
\hline ND_I_SH & $10.4 \pm 2.2$ & $1.6 \pm 0.3$ & $3.2 \pm 1.2$ & 2.1 & 4029.54 & 0.902 \\
\hline D_I_SH & $13.8 \pm 3.8$ & $0.9 \pm 0.2$ & $1.2 \pm 0.9$ & 12.8 & 4247.60 & 0.898 \\
\hline ND_II_SH & $10.9 \pm 3.8$ & $4.2 \pm 2.3$ & $5.0 \pm 1.2$ & 0.5 & 4218.79 & 0.898 \\
\hline D_II_SH & $3.2 \pm 1.7$ & $6.9 \pm 4.8$ & $1.4 \times 10^{-3} \pm 5.4 \times 10^{-2}$ & 319.4 & 5676.47 & 0.873 \\
\hline
\end{tabular}

${ }^{1}$ The measurement units of $\boldsymbol{K}_{\text {global }}$ are L L/(mol min $\left.\mathrm{g}_{\text {cat }}\right)$ for the models ND_I_SH, D_I_SH and ND_II_SH and L ${ }^{1.5} /\left(\mathrm{mol}^{0.5} \mathrm{~min}_{\text {cat }}\right)$ for the model D_II_SH.

Table 7: Estimated parameters for the Langmuir-Hinshelwood models with four parameters.

\begin{tabular}{|c|c|c|c|c|c|c|c|}
\hline Model & $K_{\text {global }}{ }^{1}$ & $\begin{array}{c}K_{s} \\
(\mathbf{L} / \mathbf{m o l}) \\
\end{array}$ & $\begin{array}{c}K_{H} \\
(\mathrm{~L} / \mathrm{mol})\end{array}$ & $\begin{array}{c}K_{e} \\
(\mathrm{~L} / \mathrm{mol}) \\
\end{array}$ & $\begin{array}{c}k \\
\left(\mathrm{~mol} /\left(\mathrm{min} \mathrm{g}_{\mathrm{cat}}\right)\right) \\
\end{array}$ & $\begin{array}{l}\text { Objective } \\
\text { Function }\end{array}$ & $\mathbf{R}^{2}$ \\
\hline ND_I_SEH & $31.5 \pm 14.9$ & $3.6 \pm 1.4$ & $4.3 \pm 1.9$ & $2.2 \pm 0.9$ & 2.0 & 2985.77 & 0.934 \\
\hline D_I_SEH & $33.3 \pm 11.6$ & $1.6 \pm 0.5$ & $1.3 \pm 0.6$ & $1.2 \pm 0.5$ & 15.5 & 3256.19 & 0.929 \\
\hline ND_II_SEH & $38.7 \pm 7.4$ & $16.7 \pm 6.0$ & $3.8 \pm 1.5$ & $10.7 \pm 2.7$ & 0.6 & 3162.72 & 0.927 \\
\hline D_II_SEH & $35.4 \pm 22.8$ & $73.0 \pm 47.8$ & 0 & $49.2 \pm 39.3$ & - & 4382.28 & 0.904 \\
\hline
\end{tabular}

${ }^{1}$ The measurement units of $K_{\text {global }}$ are L ${ }^{2} /\left(\mathrm{mol} \mathrm{min} \mathrm{g}_{\mathrm{cat}}\right)$ for the models ND_I_SEH, D_I_SEH and ND_II_SEH and L ${ }^{1.5} /\left(\mathrm{mol}^{0.5} \mathrm{~min}_{\mathrm{ccat}}\right)$ for the model D_II_SEH. 

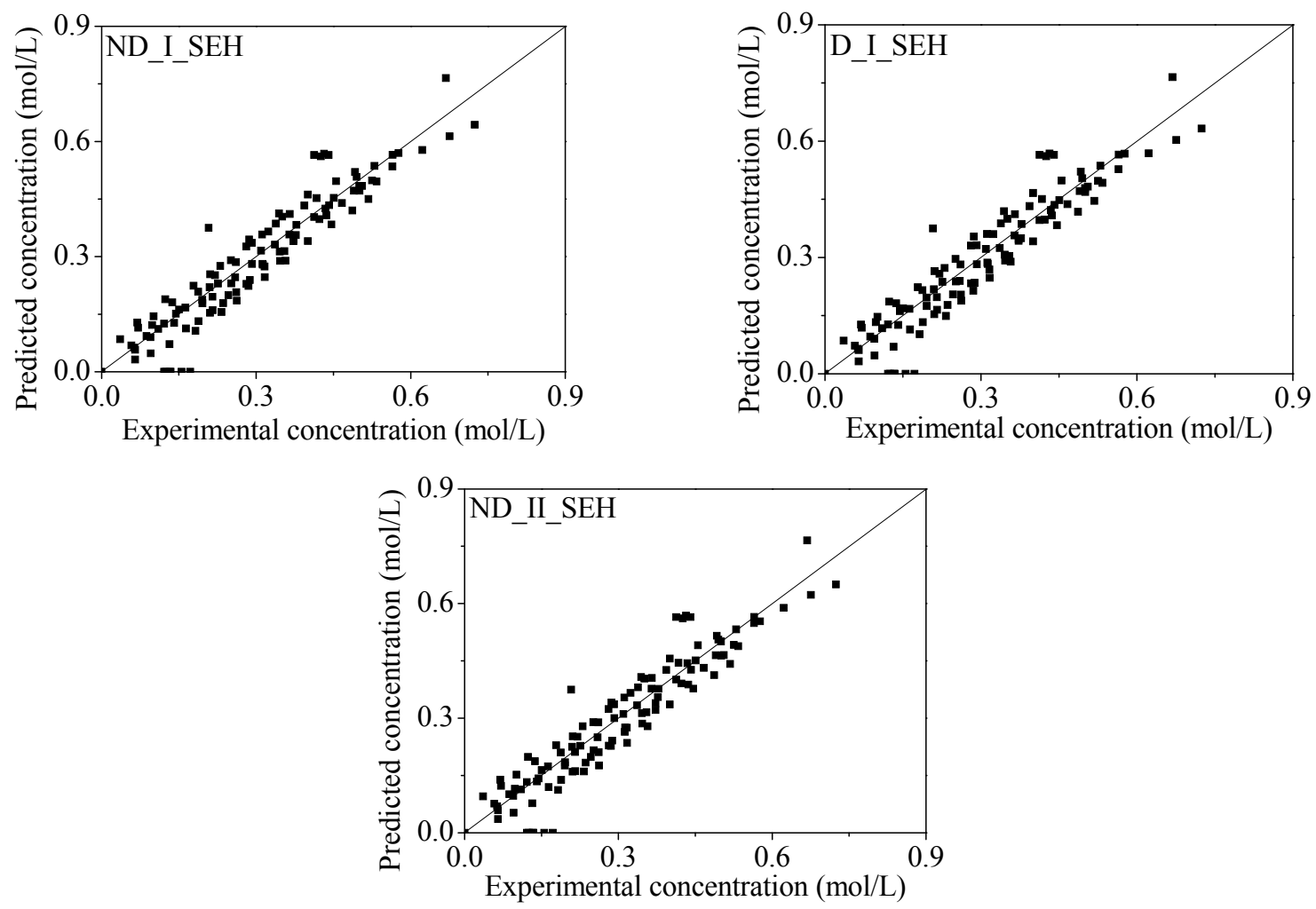

Figure 2: Fittings of the Langmuir-Hinshelwood models with 4 parameters.

The equilibrium constants for styrene and hydrogen adsorption estimated in this work can be compared with the ones calculated according to Zhou et al. $(2007 ; 2010)$, conducted in a temperature range of $40-70{ }^{\circ} \mathrm{C}$ for the catalyst $\mathrm{Pd} / \mathrm{Al}_{2} \mathrm{O}_{3}$. Extrapolating the results to $80^{\circ} \mathrm{C}$, the equilibrium constants for styrene and hydrogen adsorption are equal to $4 \mathrm{~L} / \mathrm{mol}$ and 32 $\mathrm{L} / \mathrm{mol}$, respectively. The first result is similar to that found for the models ND_I_SE, ND_I_SEH and ND_II_SH, but much different from the other models analyzed. According to the results obtained by Nijhuis et al. (2003) with a $\mathrm{Pd} / \mathrm{Al}_{2} \mathrm{O}_{3}$ catalyst at $50{ }^{\circ} \mathrm{C}$, the equilibrium constant for styrene adsorption is $13.3 \pm$ $3.1 \mathrm{~L} / \mathrm{mol}$. This result is similar to that for the model ND_II_SEH. However, it should be considered that these results were obtained at lower temperatures than this study and the adsorption equilibrium constant behaves inversely proportional to temperature.

Also according to Zhou et al. (2007; 2010), the equilibrium constant for hydrogen adsorption assumes values of $1 \times 10^{-3} \mathrm{~L} / \mathrm{mol}$ to $4 \times 10^{-3} \mathrm{~L} / \mathrm{mol}$. These values are in agreement with the model D_II_SH, but are much lower than those found in this work for the other models that consider relevant adsorption of hydrogen. However, their results can be compared to the models ND_I_SE to D_II_SE that neglect the effects of hydrogen adsorption.

The discrepancies in relation to the works of Zhou et al. $(2007 ; 2010)$ may be due to the different catalyst composition and particle size used in this study $\left(\mathrm{Pd} / 9 \% \mathrm{Nb}_{2} \mathrm{O}_{5}-\mathrm{Al}_{2} \mathrm{O}_{3}\right.$ powder) and by Zhou et al. (2007; 2010), which was egg-shell type $\mathrm{Pd} / \mathrm{Al}_{2} \mathrm{O}_{3}$. Furthermore, Zhou et al. (2007; 2010) studied the hydrogenation of a mixture of compounds (including styrene), in which there was competition for catalyst sites, a factor that can modify the parameters of the models.

\section{Effects of Temperature, Pressure and Styrene Concentration}

Based on the results with the first experimental data set, it was observed that the models ND I SE, D_I_SE, ND_I_SEH, D_I_SEH, ND_II_SEH and D_II_SEH had the best fit to the experimental data and their parameters were in agreement with other works in the field (Nijhuis et al., 2003; Zhou et al., 2007 ; 2010). Consequently, these models were chosen to investigate the effects of temperature on reaction kinetics. The estimated parameters based on 116 data points from 18 different experiments (both data sets) are presented in Tables 8 and 9 . 
Table 8: Estimated parameters for the Langmuir-Hinshelwood models with six parameters.

\begin{tabular}{|l|c|c|}
\hline Model & ND_I_SE & D_I_SE \\
\hline$a_{\text {global }}$ & $9.5 \pm 2.1$ & $9.0 \pm 2.0$ \\
$b_{\text {global }}$ & $-14.6 \pm 9.2$ & $-52.1 \pm 13.5$ \\
$a_{s}$ & $4.7 \pm 1.1$ & $2.9 \pm 0.7$ \\
$b_{s}$ & $-7.2 \pm 4.2$ & $-18.4 \pm 6.4$ \\
$a_{e}$ & $4.8 \pm 1.0$ & $3.2 \pm 0.7$ \\
$b_{e}$ & $-15.1 \pm 6.7$ & $-24.6 \pm 5.8$ \\
Objective Function & 7622.09 & 10196.00 \\
$\mathrm{R}^{2}$ & 0.868 & 0.826 \\
\hline
\end{tabular}

Table 9: Estimated parameters for the Langmuir-Hinshelwood models with eight parameters.

\begin{tabular}{|c|c|c|c|c|}
\hline Model & ND_I_SEH & D_I_SEH & ND_II_SEH & D_II_SEH \\
\hline$a_{\text {global }}$ & $2.7 \pm 0.4$ & $10.4 \pm 2.4$ & $2.7 \pm 0.3$ & $4.0 \pm 2.1$ \\
$b_{\text {global }}$ & $-1.0 \pm 11.2$ & $-69.2 \pm 18.8$ & $6.4 \pm 6.4$ & $-7.6 \pm 136.4$ \\
$a_{s}$ & $0.7 \pm 0.4$ & $3.0 \pm 0.8$ & $1.7 \pm 0.4$ & $4.3 \pm 2.1$ \\
$b_{s}$ & $-3.8 \pm 10.9$ & $-22.0 \pm 13.6$ & $2.7 \pm 1.8$ & $-9.8 \pm 145.7$ \\
$a_{H}$ & $0.4 \pm 1.1$ & $6.3 \pm 1.9$ & $0.9 \pm 1.0$ & $0.0 \pm 3.5$ \\
$b_{H}$ & $-0.1 \pm 31.7$ & $-55.1 \pm 14.7$ & $3.1 \pm 26.7$ & $-0.4 \pm 129.1$ \\
$a_{e}$ & $0.6 \pm 0.3$ & $3.3 \pm 0.8$ & $1.6 \pm 0.3$ & $4.4 \pm 2.1$ \\
$b_{e}$ & $-9.3 \pm 10.1$ & $-29.8 \pm 10.9$ & $1.4 \pm 13.8$ & $-14.9 \pm 140.9$ \\
Objective Function & 6559.14 & 9026.15 & 6229.48 & 7418.86 \\
$\mathrm{R}^{2}$ & 0.878 & 0.843 & 0.874 & 0.856 \\
\hline
\end{tabular}

All models with eight parameters presented similar determination coefficients and the model ND_I_SEH had the best fit. However, this model, as well as the models ND_II_SEH and D_II_SEH, has high errors associated with each parameter, showing that these models do not have statistical significance. This can occur because the parameters show high correlation.

It is also possible to notice that the majority of the parameters without statistical significance are of the $b_{i}$ kind, which represents the effect of temperature. The large confidence intervals of the parameters suggest that these models are over-parameterized (probably in relation to the equilibrium constant for hydrogen adsorption) and do not reproduce correctly the effect of temperature.

These problems do not occur for the models ND_I_SE and D_I_SE in Table 8 and the model D_I_SEH in Table 9. The errors associated with each parameter are smaller, which make them more statistically significant. Moreover, the models with six parameters fitted the data well, especially model ND_I SE. This corroborates the works of Zhou et al. (2007; 2010), which concluded that the equilibrium constant for hydrogen adsorption is much smaller than the ones of styrene and ethylbenzene. It also supports the hypothesis that the models with eight parameters are over-parameterized. The fittings of the models evaluated to the experimental data are shown in Figure 3.
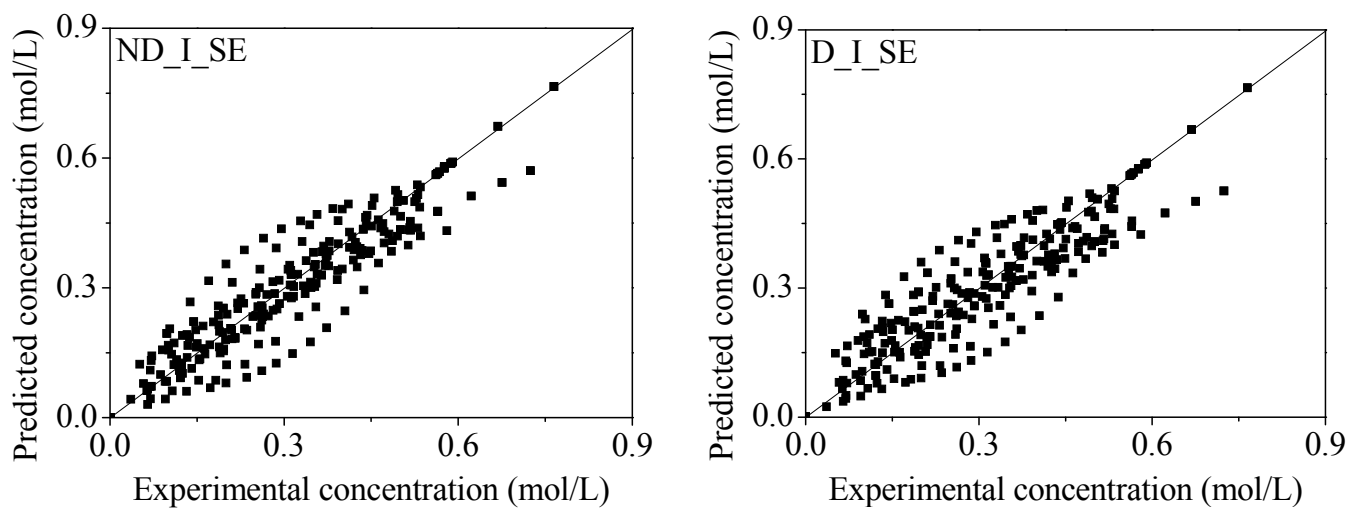

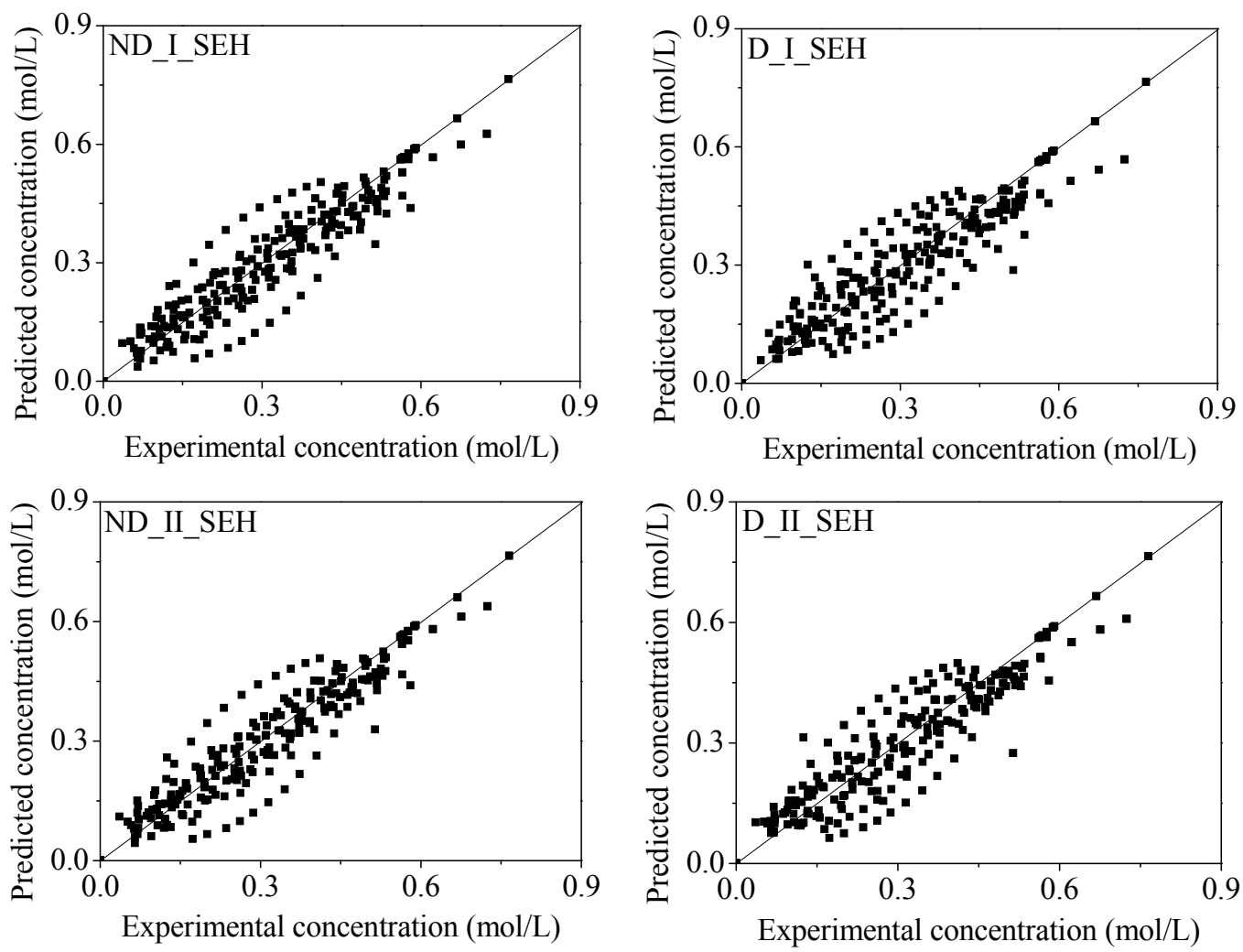

Figure 3: Fittings of the Langmuir-Hinshelwood models at several temperatures.

Table 10 shows the values calculated from each model for the apparent activation energy and heat of adsorption. For the models with six parameters, it was impossible to calculate the apparent activation energy and heat of hydrogen adsorption, since the parameters related to the equilibrium constant for hydrogen adsorption were not estimated.

Table 10: Activation energy and heat of adsorption.

\begin{tabular}{|l|c|c|c|c|}
\hline \multicolumn{1}{|c|}{ Model } & $\begin{array}{c}\boldsymbol{Q}_{\boldsymbol{s}} \\
(\mathbf{k J} / \mathbf{m o l})\end{array}$ & $\begin{array}{c}\boldsymbol{Q}_{\boldsymbol{H}} \\
(\mathbf{k J} / \mathbf{m o l})\end{array}$ & $\begin{array}{c}\boldsymbol{Q}_{\boldsymbol{e}} \\
(\mathbf{k J} / \mathbf{m o l})\end{array}$ & $\begin{array}{c}\boldsymbol{E} \\
(\mathbf{k J} / \mathbf{m o l})\end{array}$ \\
\hline ND_I_SE & -21 & - & -44 & - \\
D_I_SE & -54 & - & -72 & - \\
ND_I_SEH & -11 & -0.2 & -27 & 9 \\
D_I_SEH & -65 & -162 & -87 & 23 \\
ND_II_SEH & 8 & 9 & 9 & 2 \\
D_II_SEH & -29 & -1 & -44 & 7 \\
\hline
\end{tabular}

The apparent activation energy calculated for the model D_I_SEH presented a value close to those obtained by Nijhuis et al. (2003) and Zhou et al. (2007; 2010), which are within $26-30 \mathrm{~kJ} / \mathrm{mol}$. According to Fraga (2009), the apparent activation energy is in the range of $25-53 \mathrm{~kJ} / \mathrm{mol}$, which is also similar to the model D_I_SEH. Corvaisier et al. (2013) also estimated $23 \mathrm{~kJ} / \mathrm{mol}$ as the apparent activation energy for a Langmuir-Hinshelwood model with the same hypotheses of the model D_I_SEH. However, the results of $14.947 \mathrm{~kJ} / \mathrm{mol}$ obtained by Rojas and Zeppieri (2014) and $76.2 \mathrm{~kJ} / \mathrm{mol}$ estimated by Betti et al. (2016) differ from those obtained in this work. For the other models, the values calculated are too small and inconsistent with the apparent activation energy of a chemical reaction (Nijhuis et al., 2003).

The models ND_I_SE and D_II_SEH provided values for the heat of styrene adsorption close to the value of $-24 \mathrm{~kJ} / \mathrm{mol}$ in the work of Abreu et al. (2013). The model ND_I_SEH, however, gave results similar to those of Zhou et al. $(2007 ; 2010)$, which were $10.71 \mathrm{~kJ} / \mathrm{mol}$ and $-13.412 \mathrm{~kJ} / \mathrm{mol}$, respectively. The models D_I_SE and D_I_SEH were close to Betti et al. (2016), which obtained $-54.0 \mathrm{~kJ} / \mathrm{mol}$. For the heat of hydrogen adsorption, the result of model D_I_SEH was comparable to the studies of Abreu et al. (2013) and Betti et al. (2016), who found $-177 \mathrm{~kJ} / \mathrm{mol}$ and $108.9 \mathrm{~kJ} / \mathrm{mol}$, respectively. Reference values for the heat of ethylbenzene adsorption were found only in the work of Betti et al. (2016) as $-54.4 \mathrm{~kJ} / \mathrm{mol}$, a result relatively close to those of the models ND_I_SE and D_II_SEH. 
Since the model ND_II_SEH led to positive values for the heat of adsorption, it is in disagreement with the existing literature (Zhou et al., 2007; 2010). A possible explanation for this anomaly is one of the hypotheses of the model: it considers non-dissociative adsorption of hydrogen. The same consideration is used as a starting point for model ND_I_SEH, which gave a heat of hydrogen adsorption very close to zero. This is an indication that this hypothesis is not adequate to predict the phenomenon. Even though good fits were obtained, these models contain parameters without physical significance.

Based on the models evaluated and the corresponding estimated parameters, the equilibrium constants for styrene and hydrogen adsorption were calculated at $80{ }^{\circ} \mathrm{C}$. These values are presented in Table 11 and can be compared with the works of Zhou et al. (2007; 2010), using a $\mathrm{Pd} / \mathrm{Al}_{2} \mathrm{O}_{3}$ catalyst. In these works, the authors obtained $4 \mathrm{~L} / \mathrm{mol}$ and 32 $\mathrm{L} / \mathrm{mol}$, respectively, for the equilibrium constant for styrene adsorption. The first result is similar to the models ND_I_SEH and ND_II_SEH, but differs greatly from all other models. The second value, though, is close to the models D_I_SE and D_I_SEH.

Table 11: Equilibrium constants of styrene and hydrogen adsorption at $80^{\circ} \mathrm{C}$.

\begin{tabular}{|l|c|c|}
\hline \multicolumn{1}{|c|}{ Model } & $\boldsymbol{K}_{\boldsymbol{s}} \mathbf{( \mathbf { L } / \mathbf { m o l } )}$ & $\boldsymbol{K}_{\boldsymbol{H}}(\mathbf{L} / \mathbf{m o l})$ \\
\hline ND_I_SE & 107.2 & - \\
D_I_SE & 18.9 & - \\
ND_I_SEH & 2.1 & 1.5 \\
D_I_SEH & 20.4 & 513.3 \\
ND_II_SEH & 5.5 & 2.5 \\
D_II_SEH & 76.1 & 1 \\
\hline
\end{tabular}

According to Nijhuis et al. (2003), also with a $\mathrm{Pd} / \mathrm{Al}_{2} \mathrm{O}_{3}$ catalyst, at $50{ }^{\circ} \mathrm{C}$, the equilibrium constant for styrene adsorption is $13.3 \pm 3.1 \mathrm{~L} / \mathrm{mol}$. This result is in agreement with model D_I_SE; however, it is necessary to remember that it was obtained at a lower temperature than the ones used in this work, and the equilibrium constant for adsorption decreases as the temperature increases.

In the work of Abreu et al. (2013), with a Pd$\mathrm{Ni} / \mathrm{Al}_{2} \mathrm{O}_{3}$ catalyst, the equilibrium constant for styrene adsorption at $80{ }^{\circ} \mathrm{C}$ is $4.8 \mathrm{~L} / \mathrm{mol}$. This value is close to the one obtained by the models ND_I_SEH and ND_II_SEH.

Fraga (2009) tested a commercial $\mathrm{Pd} / \mathrm{Al}_{2} \mathrm{O}_{3}$ catalyst at temperatures between $100-120^{\circ} \mathrm{C}$, obtaining equilibrium constants for styrene adsorption between $21-42 \mathrm{~L} / \mathrm{mol}$, which are close to the models D_I_SE and D_I_SEH.

The values obtained in this work for the equilib- rium constant for hydrogen adsorption, mainly in the model D_I_SEH, are much higher than the values of $2 \times 10^{-3}$ and $7 \times 10^{-4} \mathrm{~L} / \mathrm{mol}$ found in the works of Zhou et al. $(2007 ; 2010)$, respectively.

\section{CONCLUSIONS}

This study evaluated kinetic models of the powerlaw and Langmuir-Hinshelwood types for the hydrogenation of styrene. It was observed that the powerlaw models cannot describe well the experimental data. Among the evaluated Langmuir-Hinshelwood models, the models ND_I_SE and ND_I_SEH showed the best fit to the experimental data, which consider the non-dissociative adsorption of hydrogen and adsorption of organic compounds on the same type of catalytic site. However, the last model presented high values for the equilibrium constant for hydrogen adsorption when compared with values found in literature, besides the lack of statistical significance of its parameters.

\section{ACKNOWLEDGMENTS}

We thank CNPq, ANP, FINEP and PRH-13 for the financial support.

\section{REFERENCES}

Abreu, B. M. N. B., Modesto, F. L. A., Travalloni, L. and Silva, M. A. P., Kinetic modeling of styrene hydrogenation. In Proceedings of EuropaCat-XI, Lyon, France (2013).

Alegre, V. V., Silva, M. A. P. and Schmal, M., Catalytic combustion of methane over palladium alumina modified by niobia. Catal. Commun., 7, 314 (2006).

Ali, J., The Hydrogenation of Pyrolysis Gasoline (PyGas) Over Nickel and Palladium Catalysts. Ph.D. Thesis, School of Chemistry University of Glasgow (2012).

Betti, C., Badano, J., Lederhos, C., Maccarrone, M., Carrara, N., Coloma-Pascual, F., Quiroga, M. and Vera, C., Kinetic study of the selective hydrogenation of styrene over a Pd egg-shell composite catalyst. Reac. Kinet. Mec. Cat., 117, 283 (2016).

Cheng, Y-M., Chang, J-R. and Wu, J-C., Kinetic study of pyrolysis gasoline hydrogenation over supported palladium catalyst. App. Catal., 24, 273 (1986).

Corvaisier, F., Schuurman, Y., Fecant, A., Thomazeau, C., Raybaud, P., Toulhoat, H. and Farrusseng, D., 
Periodic trends in the selective hydrogenation of styrene over silica supported metal catalysts. J. Catal., 307, 352 (2013).

Fraga, E. B., Modelagem de um Reator de Hidrogenação de Gasolina de Pirólise Industrial. M. Sc. Thesis, COPPE, Universidade Federal do Rio de Janeiro (2009). (In Portuguese).

Gaspar, A. B., Santos, G. R., Costa, R. S., Silva, M. A. P. and Britto, J. M., Hydrogenation of synthetic PYGAS-Effects of zirconia on $\mathrm{Pd} / \mathrm{Al}_{2} \mathrm{O}_{3}$. Catal. Today, 133, 140 (2008).

Hoffer, B. W., Bonné, R. L. C., Langeveld, A. D., Griffiths, C., Lok, C. M. and Moulijn, J. A., Enhancing the start-up of pyrolysis gasoline hydrogenation reactors by applying tailored ex situ presulfided $\mathrm{Ni} / \mathrm{Al}_{2} \mathrm{O}_{3}$ catalysts. Fuel, 83, 1 (2004).

Jackson, S. D. and Shaw, L. A., The liquid-phase hydrogenation of phenyl acetylene and styrene on a palladium/carbon catalyst. App. Catal. A: Gen., 134, 91 (1996).

Medeiros, J. L., Araújo, O. Q. F., Gaspar, A. B., Silva, M. A. P. and Britto, J. M., A kinetic model for the first stage of PYGAS upgrading. Braz. J. of Chem. Eng., 24, 119 (2007).

Mostoufi, N., Ahmadpour, M. and Sotudeh-Gharebagh, R., Modelling the two-stage pyrolysis gasoline hydrogenation. Comp. Aid. Chem. Eng., 20, 451 (2005).

Nelder, J. A. and Mead, R., A Simplex method for function minimization. The Comp. J., 7(4), 308 (1965).

Nijhuis, T. A., Dautzenberg, F. M. and Moulijn, J. A., Modeling of monolithic and trickle-bed reactors for the hydrogenation of styrene. Chem. Eng. Sci., 58, 1113 (2003).

Rojas, M. and Zeppieri, S., Simulation of an industrial fixed-bed reactor with cocurrent downflow for hydrogenation of PYGAS. Catal. Today, 220, 237 (2014).

Schwaab, M. and Pinto, J. C., Optimum reparameterization of power function models. Chem. Eng. Sci, 63, 4631 (2008).
Secchi, A. R. and Perlingeiro, C. A. G., Otimização: Busca Aleatória Adaptativa. Anais do XII Congresso Nacional de Matemática Aplicada e Computacional (XII CNMAC), São José do Rio Preto, SP, 49 (1989). (In Portuguese).

Soares, R. P. and Secchi, A. R., EMSO: A New Environment for Modelling, Simulation and Optimization. ESCAPE 13, 947 (2003).

Tukac, V., Simícková, M. Chyba, V., Lederer, J., Kolena, J., Hanika, J., Jiricny, V., Stanek, V. and Stavárek, P., The behavior of pilot trickle-bed reactor under periodic operation. Chem. Eng. Sci., 62(18-20), 4891 (2007).

Vale, C. S. A., Hidrogenação de gasolina de pirólise empregando catalisadores à base de paládio. Final Project, Escola de Química, Universidade Federal do Rio de Janeiro (2013). (In Portuguese).

Wen, X., Li, R., Yang, Y., Chen, J. and Zhang, F., An egg-shell type $\mathrm{Ni} / \mathrm{Al}_{2} \mathrm{O}_{3}$ catalyst derived from layered double hydroxides precursor for selective hydrogenation of pyrolysis gasoline. App. Catal. A: Gen., 468, 204 (2013).

Wolffenbuttel, B. M. A., Nijhuis, T. A., Stankiewicz, A. and Moulijn, J. A., Influence of water on fast hydrogenation reactions with monolithic and slurry catalysts. Catal. Today, 69, 265 (2001).

Zeng, T. Y., Zhou, Z. M., Zhu, J., Cheng, Z. M., Yuan, P. Q. and Yuan, W. K., Palladium supported on hierarchically macro-mesoporous titania for styrene hydrogenation. Catal. Today, 147S, S41 (2009).

Zhou, Z., Cheng, Z., Cao, Y., Zhang, J., Yang, D. and Yuan, W., Kinetics of the selective hydrogenation of pyrolysis gasoline. Chem. Eng. Technol., 30, 105 (2007).

Zhou, Z., Cheng, Z., Yang, D., Zhou, X. and Yuan, W., Solubility of hydrogen in pyrolysis gasoline. J. Chem. Eng., 51, 972 (2006).

Zhou, Z., Zeng, T., Cheng, Z. and Yuan, W., Kinetics of selective hydrogenation of pyrolysis gasoline over an egg-shell catalyst. Chem. Eng. Sci., 65, 1832 (2010). 